\title{
Ear Gel Dosage Form
}

National Cancer Institute

\section{Source}

National Cancer Institute. Ear Gel Dosage Form. NCI Thesaurus. Code C149454.

Semi-solid single-dose or multidose preparation consisting of a gel intended for application to the external auditory meatus, if necessary by means of a tampon impregnated with the preparation. 